\title{
Reading Between Blurred Lines: The Complexity of Interpretation
}

\begin{abstract}
This article uses thematic qualitative analysis and techniques from corpus linguistics to interrogate the way that listeners interpret and make sense of Blurred Lines. The song was controversial upon its release as many listeners felt that it implied that even if women said they did not want sex, in fact, they did. Such issues of sexual consent are a key issue for feminist analysis, particularly within current debates about 'rape culture'. We investigated listeners' interpretations of the song, distributing an online questionnaire to over 1000 respondents. We found that most listeners either interpreted the song as relating to sexual consent and took offence, or felt that it was simply representative of the genre, and found the song unproblematic. However, a number of listeners expressed conflict in relation to the song, enjoying it musically but finding the lyrics particularly problematic. Our analysis investigates the language that respondents used to negotiate their relationships with the different elements of the song.
\end{abstract}

Key words: Blurred Lines; sexual consent; rape culture; discourse analysis; corpus linguistics

\section{Introduction}

Blurred Lines (written by Robin Thicke, T.I. and Pharrell Williams) reached number one in fourteen countries and was the biggest-selling single in the world in 2013 (IFPI, 2014). At the time of writing, the official version of the song has been viewed 500, 913, 572 times on YouTube. It now has a content warning stating that 'this video may be inappropriate for some users', but this is a recent addition. This warning reflects the controversy that the song provoked, with critics associating it with issues of sexual consent (henceforth referred to as a consent-based reading), suggesting it indexed discourses of sexual violence; the lyrics 'I hate these Blurred Lines' and 'I know you want it' were particular targets for reproach.

The consent-based reading of Blurred Lines, debated widely in the press, suggests that the song is promoting or supporting a view that women want to have sex despite stating otherwise; hence the 'blurred lines' between consent and resistance. Lai (2013) notes that the song was labelled 'rapey' and Romano (2013) comments that 'the song is about how a girl really wants crazy wild sex but doesn't say it - positing that age-old problem where men think no means yes into a catchy, hummable song'. Claims that the song expressed 'rape culture' - defined by Bushwald, Fletcher and Roth (2005:xi) as 'a complex set of beliefs that encourages male sexual aggression and supports violence against women' and where 'the clear line between rape and consensual sex can no longer be drawn with confidence' (Kelley, 2008:129) - were vehemently denied by the song's writers. Alternative readings of the song are possible. Those opposing consent-based readings argued that the song was more complex and playful than critics assumed, and claimed it was prudish to take offence.

To investigate how the song was received by the (UK) general public, we administered an online questionnaire to 1024 respondents who read the song's lyrics and watched the music video. Our analysis utilises corpus linguistics methods and close reading to interrogate different possible readings of the song, and examines the wider discourses that respondents drew upon. We show that respondents largely viewed the song/video as consent-related, but also that for many, their perceptions was that (partially due to its form as a pop song with a danceable tune) the song was playful, and did not endorse (implicitly or otherwise) sexual violence. Thus, 
listeners found the process of understanding the song more complicated than merely accepting or rejecting the consent-based reading.

The following section summarises relevant research on lyric analysis, section 3 discusses work on gender representation in music videos, the methodology is provided in section 4, and section 5 includes our analysis, which focuses on representations of gender in the video, interpretations of lyrics, and discussions of sexual consent. We consider the wider ramifications of our findings in section 6 .

\section{Negotiating meaning in song lyrics}

Existing research on the interpretation of lyrics (c.f. Dibben 1999:331) has focused on considering the extent to which listeners' understandings of a song are constrained by properties of the song itself and explores how songs make 'ideology material'. Dibben (1999:331) argues that 'meanings are the result of convergence between material properties of a text, and the particular social allegiances of the reader'. This means that despite each listener hearing the same music and lyrics, their particular beliefs and social experiences shape their conceptualisation of a song's meaning; thus interpretations of linguistic meaning are variable, socially constructed and liable to change.

Dibben (1999:332) suggests that each song has a 'subject position', defined as 'the ethical position which the material encourages the listener to adopt towards the social content'. In Blurred Lines, this position would be one where the listener accepts and empathises with Thicke's perception (as primary vocalist) that there are 'blurred lines' in the initiation of heterosexual relationships. The genre of the song (funk, with its prominent bass line) encourages this heteronormative sexual interpretation of the subject position, as funk is traditionally associated with 'the expression of male sexuality' (Dibben, 1999:345). Blurred Lines also includes a rap by T.I. which sets it within a masculinist discourse; rap, particularly gangster rap, is frequently associated with an overtly misogynistic and violent masculinity, with women being viewed solely as objects of male desire (Dibben, 1999:345; Kubrin, 2005:306; Skeggs, 1994:110). Durham (2012) argues that popular music is permeated with this hip-hop vision of hypermasculinity, wealth display, and sexually available women. This combination of the genre, and the dominance of the two male voices suggests that Blurred Lines is encouraging listeners to view the pursuit of sexual gratification from the subject position of a heterosexual male, whose masculinity can be considered at times overtly misogynistic (but, according to the writers, not criminal or violent). Those rejecting a consentbased reading of the song tend to accept this subject position and feel that an awareness of 'blurred lines' does not equate with sexual violence; the song's subject is not a rapist.

However, it is possible to reject this subject position, viewing Blurred Lines as contributing to rape culture. One justification for the consent-based reading of Blurred Lines is that its lyrics index discourses of sexual violence. Critics drew direct comparisons between the lyrics and the words used by rapists during and/or after attacks. For example, Project Unbreakable (2014) collected photographs of rape and sexual assault survivors pictured alongside the words spoken by their attackers. These quotes include 'I know you want this... so open up and don't tell anyone' and 'Stop lying, I know this is what you want'. These words are mirrored in the key refrain of Blurred Lines - 'I know you want it' - independent of the songwriters' intent.

In a similar vein, Horvarth, Hegarty, Tyler and Mansfield (2012) demonstrated that young men and women struggled to tell the difference between quotes from media texts (specifically UK lads' mags) and quotes from convicted rapists. Their results showed that respondents correctly 
attributed only quotes $56.1 \%$ and $55.4 \%$ of the time, respectively, suggesting that respondents perceived some linguistic similarities between the two sets of quotations. Respondents also noted that the idea of miscommunication influenced their decisions: 'I've always thought as rapists as men that don't understand signals from women [...] saying no but really they mean yes' (Horvarth et al. 2012:465). Such sentiments are embedded within the subject position of Blurred Lines, where the singer apparently cannot interpret the signals being given by the object of his affections. Horvarth et al. (2012:467) note that 'the 'mainstream' status' of lads' magazines allows them to 'legitimize views about women that young men [and women] might otherwise consider unacceptable'. If such print media can be seen to influence views of male and female (hetero)sexuality, then arguably the same weight can be given to the lyrics (and videos) of popular music such as Blurred Lines.

\section{Gender Performativity and Representation in Popular Music}

As the visual representations of songs, music videos situate lyrics within a particular narrative, and therefore perform a powerful semiotic role in the interpretation of songs. Despite the potential for music videos to represent women as 'independent, strong, and self-reliant agents of their own desire' (Emerson, 2002:116), Ward et al. (2005:144) suggest that the world of music videos is an 'arena where images of powerful and dominant men and of sexually objectified women are especially prevalent'. Seidman (1992) shows that in music videos women are the recipients/initiators of sexual advances more than men, and are often depicted in 'revealing clothing'. In the Blurred Lines video, men wear suits and trousers, whilst women wear underwear, nude-coloured clothing and transparent plastic dresses. The video begins with singer Robin Thicke in bed wearing a white collared shirt beside a woman who is partially naked.

Feminist research (Bates, 2014; Baxter and Coslett, 2014; Gill, 2006; Walter, 2010) has focused on the way that women are represented across a range of different media as sexualised and as complicit in their own sexual exploitation. Hansen and Hansen (1990), have expressed concern about the effects of this on younger audiences, whilst Johnson et al. (1995) and Kalof (1999) identified alterations in attitudes towards violence among respondents exposed to music videos that included implicit sexual violence. The sexualisation of women in music videos is also achieved through more implicit means. In their study of early-nineties' music videos, Sommers-Flanagan, Sommers-Flanagan and Davis (1993) observed that 'implicit sexuality', expressed through actions such as 'long lip licking', is a prominent feature. Semiotic resources such as lip licking and finger sucking appear in both the pre-watershed and unrated versions of the Blurred Lines video.

This study takes a feminist discourse analytical approach to audience responses to Blurred Lines and is underpinned by performative understandings of gender identity (Butler 1990; 1993). In this model of gender, repeated linguistic (and non-linguistic) practices are viewed as constitutive; thus gender is something you do rather than something you have. However, most relevant to this study is the performative nature of gender: 'a set of repeated acts within a highly rigid regulatory frame that congeal over time to produce the appearance of substance of a natural sort of being' (Butler 1990: 33). What we understand as normative gender performances are instantiated through repeated reference to particular discourses, or 'ways of seeing the world' (Fairclough 1992). Thus, as with any kind of linguistic meaning, conceptualisations of gender identity are dependent on consensus. As Goffman (1976) argues, 'our gendered behaviour, as well as our concepts of masculinity and femininity are scripts that are dictated by our environment that we consciously and unconsciously learn and perform, in order to play our appropriate roles in society' (cited in Wallis, 2011:161). 
Drawing on Butler's $(1990 ; 1993)$ work, we argue that we are interpellated by representations of masculinity and femininity according to how they are constructed in our immediate environment. Gauntlett (2008:27) describes how 'interpellation occurs when a person connects with a media text: when we enjoy a magazine or TV show, for example, this uncritical consumption means that the text has interpellated us into a certain set of assumptions, and caused us to tacitly accept a particular approach to the world'. What we are interested in here are the 'assumptions' that audiences draw on in their responses to Blurred Lines and what this reveals about their negotiation of normative understandings of gender and sexuality.

\section{Methodology}

We wanted to examine the range of readings of Blurred Lines to demonstrate that listeners did not simply agree with the subject position of the song, where they would empathise with Thicke's perception that there are 'blurred lines' in the initiation of heterosexual relationships, or the consent-based reading widely taken by the media, or the argument that the song is merely playful. We used Survey Monkey (www.surveymonkey.net) to gather responses, specifically addressing the following research questions:

1. What discourses do respondents draw on when discussing Blurred Lines?

2. How do respondents evaluate representations of women and men in the music video?

3. How do respondents construct their interpretations of the song's lyrics?

4. Do respondents accept the consent-based reading of Blurred Lines?

1024 anonymous respondents completed the questionnaire (Appendix A), with 69\% identifying as female and $31 \%$ male. We used a snowball sampling method, using local radio, email, and social media platforms (Twitter/Facebook) to contact as many potential respondents as possible. This method of data collection attracted a self-selecting population, but we wanted to canvass the opinions of those who had strong feelings (positive and negative) about the song/video. More than half of respondents were 30 or younger $(52.89 \%)$, with the largest age category being 26-30 year olds (27.23\%). We are aware from context provided by some respondents in the open questions that most, but not all were UK-based. However, as Blurred Lines was a global hit, it is not problematic to include respondents from different geographical locations and/or cultural backgrounds. By making the survey anonymous we hoped to encourage participation from a wide range of respondents. Despite this, our channels of distribution (noted above) attracted a predominantly British audience.

Our questionnaire (Appendix A) included closed questions to capture respondents' overarching views of the song, but also included open questions to elicit interpretations of particular lyrics, views of men and women in the video, and understandings of the term 'blurred lines'. The qualitative responses (comprising 95, 320 words in total) were saved as separate text files for each question to facilitate corpus analysis. Drawing on a growing tendency for using corpus linguistics to analyse gender (see Baker 2014), and in a similar vein to Jaworska and Krishnamurthy's (2012) analysis of media representations of feminism, we used elements of corpus linguistics such as keywords, key semantic domains, and collocations to interrogate our data. Unlike Jaworska and Krishnamurthy, our analysis focused on public responses to a mass media text (Blurred Lines) rather than analysis of a media text. We are not focused on content of the song's lyrics/music video, but on respondents' interpretations of them. Thus our work differs from existing corpus-based work on pop music, such as Werner's (2012) analysis of pop lyrics, and makes a methodological contribution to the field. 
We first calculated keywords and key semantic domains for the whole corpus of responses and then for each individual question using Wmatrix (Rayson 2009), with its inbuilt sample of the British National Corpus (a corpus of general English) as a reference corpus. These calculations pointed us towards salient terms for close analysis at the discourse level using Nvivo 10 (2012). We also analysed the collocates of the lemmas MAN and WOMAN (section 5.2) in respondents' comments about the music video. The analysis of collocation patterns is useful for revealing relationships between words and highlighting patterns in how particular concepts are constructed. Collocation and semantic domain analysis are particularly useful for observing the "incremental effect of discourse" (Baker 2006: 13), by collecting numerous instances of language that point to particular discourse constructions. As a form of triangulation, NVivo was used to code all qualitative data, using a combination of a priori (deductive) and empirical (inductive) coding. Inductive codes such as 'consent' and 'media response' were used because of our interest in respondents' views on these matters. Further empirical codes were added as the analysis progressed. For example, it became clear that respondents used the word 'choice' both in relation to sexual consent and the choice of the women who appeared in the video as dancers. This mixed-methods approach was chosen because the software available for conducting qualitative and quantitative text analysis in the social sciences have different strengths. NVivo was useful for observing overarching themes, whilst the corpus tools facilitated the statistical analysis of linguistic patterns and highlighted features that might otherwise have been overlooked (such as the prominence of 'but', discussed in section 5.1).

\section{Analysis}

Responses to the questionnaire highlighted a breadth of opinions about Blurred Lines, with differing reactions to the song and the video as separate entities. Although the majority of respondents (74\%) expressed negative feelings about the video, some individuals liked it, and a number indicated a degree of ambivalence. The majority dislike of the song could suggest an overall acceptance of the consent-based reading of the lyrics and video. However, there are many reasons not to like a song. Below, we examine the nuances of respondents' reactions in order to show the range of different positions evidenced in our data. We focus on respondents' reported reactions upon hearing the song (section 5.1), their interpretations of the depictions of women and men in the video (section 5.2), their responses to a subset of the song's lyrics (section 5.3), and their views on whether the song refers to sexual consent (section 5.4).

To provide an initial overview of our data, keyword and key semantic domain analysis revealed which concepts are the most salient to our respondents. Table 1 shows that top 20 keywords for all questions combined and Table 2 provides the corresponding semantic domain data.

\begin{tabular}{|l|l|l|l|l|l|l|}
\hline Rank & Item & $\begin{array}{l}\text { Freq. in } \\
\text { data }\end{array}$ & $\begin{array}{l}\text { Relative freq. } \\
\text { in data }\end{array}$ & $\begin{array}{l}\text { Freq. in BNC } \\
\text { sampler }\end{array}$ & $\begin{array}{l}\text { Relative freq. in } \\
\text { BNC sampler }\end{array}$ & $\begin{array}{l}\text { Log-likelihood } \\
\text { score }\end{array}$ \\
\hline 1 & sex & 568 & 1.05 & 12 & 0 & 3244.27 \\
\hline 2 & women & 648 & 1.2 & 141 & 0.01 & 3107.32 \\
\hline 3 & song & 272 & 0.51 & 24 & 0 & 1444.9 \\
\hline 4 & woman & 269 & 0.5 & 113 & 0.01 & 1139.28 \\
\hline 5 & lyrics & 165 & 0.31 & 1 & 0 & 963.89 \\
\hline 6 & rape & 163 & 0.3 & 2 & 0 & 942.76 \\
\hline
\end{tabular}




\begin{tabular}{|l|l|l|l|l|l|l|}
\hline 7 & men & 261 & 0.48 & 197 & 0.02 & 938.93 \\
\hline 8 & video & 196 & 0.36 & 68 & 0.01 & 865.4 \\
\hline 9 & sexual & 145 & 0.27 & 6 & 0 & 807.88 \\
\hline 10 & attractive & 144 & 0.27 & 16 & 0 & 749.47 \\
\hline 11 & objectified & 116 & 0.22 & 0 & 0 & 686.16 \\
\hline 12 & girl & 203 & 0.38 & 198 & 0.02 & 666.06 \\
\hline 13 & penis & 109 & 0.2 & 0 & 0 & 644.75 \\
\hline 14 & sexually & 88 & 0.16 & 1 & 0 & 509.68 \\
\hline 15 & objects & 88 & 0.16 & 6 & 0 & 476.55 \\
\hline 16 & naked & 69 & 0.13 & 8 & 0 & 357.63 \\
\hline 17 & bitch & 71 & 0.13 & 18 & 0 & 332.27 \\
\hline 18 & girls & 94 & 0.17 & 79 & 0.01 & 325.93 \\
\hline 19 & compliment & 53 & 0.1 & 2 & 0 & 296.53 \\
\hline 20 & creepy & 51 & 0.09 & 1 & 0 & 291.9 \\
\hline
\end{tabular}

Table 1: Top 20 lexical keywords in the Blurred Lines questionnaire responses

\begin{tabular}{|c|c|c|c|c|c|c|}
\hline Rank & $\begin{array}{l}\text { Key semantic } \\
\text { domain }\end{array}$ & $\begin{array}{l}\text { Freq. in } \\
\text { BL data }\end{array}$ & $\begin{array}{l}\text { Relative freq. } \\
\text { in BL data }\end{array}$ & $\begin{array}{l}\text { Freq. in } \\
\text { BNC } \\
\text { sampler }\end{array}$ & $\begin{array}{l}\text { Relative freq. } \\
\text { in BNC } \\
\text { sampler }\end{array}$ & $\begin{array}{l}\text { Log- } \\
\text { likelihood } \\
\text { scores }\end{array}$ \\
\hline 1 & People: Female & 1355 & 2.52 & 875 & 0.09 & 5121.1 \\
\hline 2 & $\begin{array}{l}\text { Relationship: } \\
\text { Intimacy and sex }\end{array}$ & 561 & 1.04 & 549 & 0.06 & 1838.32 \\
\hline 3 & $\begin{array}{l}\text { Music and related } \\
\text { activities }\end{array}$ & 562 & 1.04 & 586 & 0.06 & 1795.88 \\
\hline 4 & Unmatched & 1198 & 2.22 & 5684 & 0.58 & 1329.77 \\
\hline 5 & People & 811 & 1.51 & 2728 & 0.28 & 1278.43 \\
\hline 6 & No respect & 136 & 0.25 & 5 & 0 & 761.78 \\
\hline 7 & People: Male & 502 & 0.93 & 1829 & 0.19 & 735.78 \\
\hline 8 & $\begin{array}{l}\text { Judgement of } \\
\text { appearance: } \\
\text { negative }\end{array}$ & 298 & 0.55 & 628 & 0.06 & 666.24 \\
\hline
\end{tabular}




\begin{tabular}{|c|c|c|c|c|c|c|}
\hline 9 & Crime & 227 & 0.42 & 290 & 0.03 & 664.66 \\
\hline 10 & $\begin{array}{l}\text { Language, speech } \\
\text { and grammar }\end{array}$ & 368 & 0.68 & 1105 & 0.11 & 638.58 \\
\hline 11 & Wanted & 835 & 1.55 & 5302 & 0.54 & 622.87 \\
\hline 12 & $\begin{array}{l}\text { The Media: TV, } \\
\text { Radio and Cinema }\end{array}$ & 263 & 0.49 & 562 & 0.06 & 582.82 \\
\hline 13 & Without clothes & 101 & 0.19 & 24 & 0 & 477.72 \\
\hline 14 & Evaluation: bad & 236 & 0.44 & 656 & 0.07 & 435.19 \\
\hline 15 & Selfish & 120 & 0.22 & 102 & 0.01 & 414.41 \\
\hline 16 & $\begin{array}{l}\text { Judgement of } \\
\text { appearance: } \\
\text { Positive }\end{array}$ & 347 & 0.64 & 1717 & 0.17 & 366.2 \\
\hline 17 & Respected & 91 & 0.17 & 94 & 0.01 & 291.89 \\
\hline 18 & Dislike & 126 & 0.23 & 286 & 0.03 & 268.47 \\
\hline 19 & Thought, belief & 746 & 1.39 & 7031 & 0.72 & 247.23 \\
\hline 20 & No constraint & 108 & 0.2 & 250 & 0.03 & 227.12 \\
\hline
\end{tabular}

Table 2: Top 20 key semantic domains in the Blurred Lines questionnaire

Taken together the keywords and key semantic domains highlighted salient themes. Keywords such as rape, objectified and objects, for example, indicate that on the whole respondents interpreted Blurred Lines as relating to debates about rape culture and feminist issues. This is supported by the prominence of <relationship: intimacy and sex> as a key semantic domain, which includes words such as sexual, sexualised, and porn, and the <crime> semantic domain, which is dominated by instances of rape, and rapist. Close reading of the data using Nvivo indicated similar themes (discussed in detail in the following sections). Thus we found comparable results regardless of the tools we used.

\subsection{Actions upon Hearing Blurred Lines}

Although the keywords listed in Table 1 might indicate that respondents agreed with the consent-based reading of the song wholesale, close reading of the data revealed the complexity and nuance of individual responses. The complex nature of individuals' attitudes towards Blurred Lines was evident when we asked respondents which of the following actions they would take upon hearing the song; (i) Sing along, (ii) Buy the song, (iii) Stream the song, (iv) Dance, (v) Change the radio/television station, (vi) Leave the dancefloor, (vii) Other (please specify). Respondents were given hyperlinks to the lyrics and video of the song and could select as many responses to this question as they wished. We also gave participants space to 
make additional comments. We received 1003 responses to this question (Figure 1), the most popular of which was 'change the radio/television station', closely followed by 'leave the dancefloor'. However, $31 \%$ of respondents would sing along whilst $23 \%$ would dance, suggesting more positive engagement with the song. Figure 1 also shows that there was very little gendered variation in reactions to the song; as such, responses are pooled for the remainder of the paper.

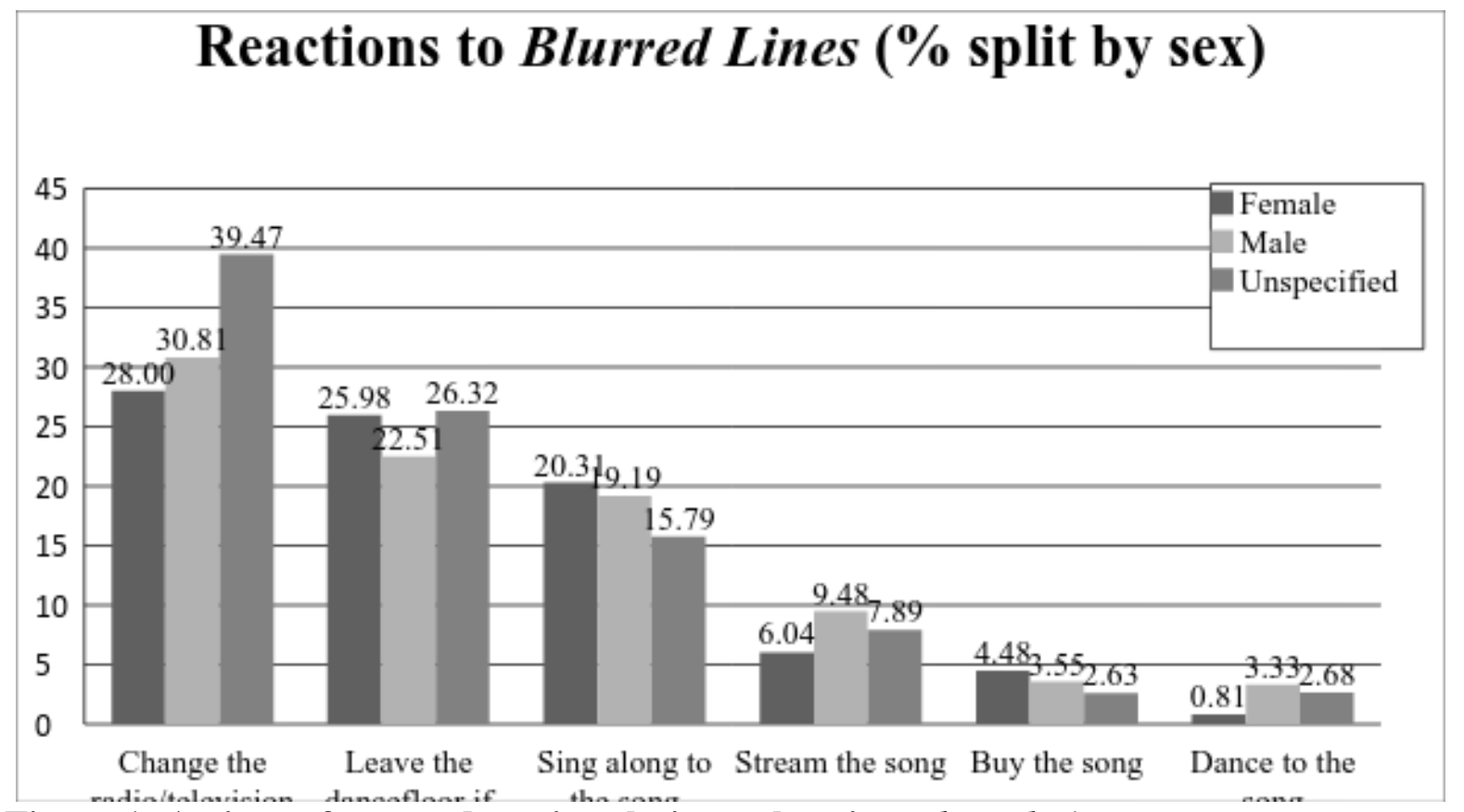

Figure 1: Actions of respondents in relation to hearing Blurred Lines

Responses to this question reflected the conflict felt by some respondents. 509 respondents selected multiple responses to this question, 32 of which appeared to contradict each other, e.g. singing along to the song but also leaving the dance floor. 182 participants provided additional comments, some of which also expressed conflict: 'conflicted - originally bought and danced to [it] until I saw the video and paid attention to the words. It now disgusts me'. Analysing the top 20 keywords in these additional comments provides further evidence of conflict (Table 3). For example, catchy is a keyword with positive connotations, but words with a negative semantic prosody, such as tolerate and annoyed, also rank highly. The word 'catchy' is among the most frequent lexical words in the qualitative responses. Occurring 11 times, it has the third-highest keyness value and is the most frequent adjective used in response to this question. It occurs a total of 44 times across all responses to all questions. Even those who disliked the song stated that 'it's a remarkably catchy pop song, despite containing remarkably misogynistic lyrics (and an even worse video) it's difficult to not sing/hum the tune if you've heard it' and 'I confess this song is a guilty pleasure, awful words and video but [I] like the music'.

\begin{tabular}{|l|l|l|l|l|l|l|}
\hline Rank & Item & $\begin{array}{l}\text { Freq. in } \\
\text { Q2 }\end{array}$ & $\begin{array}{l}\text { Relative freq. } \\
\text { in Q2 }\end{array}$ & $\begin{array}{l}\text { Freq. in BNC } \\
\text { sampler }\end{array}$ & $\begin{array}{l}\text { Relative freq. in } \\
\text { BNC sampler }\end{array}$ & $\begin{array}{l}\text { Log-likelihood } \\
\text { scores }\end{array}$ \\
\hline 1 & song & 62 & 3.37 & 24 & 0 & 677.41 \\
\hline 2 & lyrics & 11 & 0.6 & 1 & 0 & 131.36 \\
\hline 3 & catchy & 10 & 0.54 & 0 & 0 & 125.67 \\
\hline
\end{tabular}




\begin{tabular}{|l|l|l|l|l|l|l|}
\hline 4 & listen & 14 & 0.76 & 143 & 0.01 & 82.08 \\
\hline 5 & dance & 8 & 0.44 & 16 & 0 & 70.04 \\
\hline 6 & sing_along & 5 & 0.27 & 0 & 0 & 62.84 \\
\hline 7 & rape & 5 & 0.27 & 2 & 0 & 54.47 \\
\hline 8 & rant & 4 & 0.22 & 0 & 0 & 50.27 \\
\hline 9 & heard & 10 & 0.54 & 185 & 0.02 & 47.48 \\
\hline 10 & recognise & 5 & 0.27 & 8 & 0 & 45.54 \\
\hline 11 & tolerate & 4 & 0.22 & 1 & 0 & 45.27 \\
\hline 12 & loudly & 4 & 0.22 & 2 & 0 & 42.64 \\
\hline 13 & video & 7 & 0.38 & 68 & 0.01 & 41.7 \\
\hline 14 & annoyed & 5 & 0.27 & 15 & 0 & 40.4 \\
\hline 15 & parody & 3 & 0.16 & 0 & 0 & 37.7 \\
\hline 16 & Robin_Thicke & 3 & 0.16 & 0 & 0 & 37.7 \\
\hline 17 & Rapey & 3 & 0.16 & 0 & 0 & 37.7 \\
\hline 18 & ignore & 5 & 0.27 & 24 & 0 & 36.26 \\
\hline 19 & tune & 5 & 0.27 & 25 & 0 & 35.89 \\
\hline 20 & radio & 6 & 0.33 & 59 & 0.01 & 35.6 \\
\hline
\end{tabular}

Table 3: Top 20 lexical keywords in responses to actions on hearing Blurred Lines

There was also evidence of conflict in language choices that were not statistically significant, but which indicate the complexity of reactions to Blurred Lines. Analysis using NVivo revealed that words guilt (5 tokens), shame (1), annoyed (5) and disgusted (6) were used to express how the respondents felt about their own otherwise positive reactions to the song. Top collocates of these terms in the BNC reference corpus include plead, offence, manslaughter, accused, and conscience, and their use in our data suggests that respondents conceptualised their positive reactions as something negative that needed to be admitted. One stated that they would sing along to Blurred Lines, 'but I don't feel proud about it'. Furthermore, there was a pattern indicating that individuals would react differently to the song in a public space than they would in private, which suggests some respondents felt that there was a particular reaction they should have to the song - a perception likely to have been influenced by media-endorsed consentbased reading of the song and perhaps an awareness of oppositional discourses, such as feminism. Further evidence for conflicting reactions is the fact that but, a conventional marker of contrast, was the most frequent conjunction used in responses to this question. Analysing concordance lines for but (Figure 2) reveals that around half of the instances of this word (14 out of $29 ; 48 \%$ ) are used to contrast contradictory reactions to the song.

e very cross because it is so catchy but so mysogenist in content but a catchy but so mysogenist in content but also hate myself for it and all around me that the tune is good but the words a little " Rapey " i about use of the song . sing along, but then stop myself. It 's ridicu 


\begin{tabular}{|c|c|c|}
\hline $\begin{array}{l}\text { s a consequence of filling this in } \text {. } \\
\text { s Leave the establishment Sing along } \\
\text { pop music scene. I'd dance to it , } \\
\text { xt song . Stand looking unimpressed } \\
\text { ut the terrible message Object to it } \\
\text { catchy despite being gross Sing along } \\
\text { er. The rythm is very 'danceable', } \\
\text { workout to the song I am a feminist } \\
\text { the tune Obviously it 's very catchy } \\
\text { think it's sexist and disgusting - }\end{array}$ & $\begin{array}{l}\text { but } \\
\text { but } \\
\text { but } \\
\text { but } \\
\text { but } \\
\text { but } \\
\text { but } \\
\text { but } \\
\text { but }\end{array}$ & $\begin{array}{l}\text { I don't feel proud about it } \\
\text { be annoyed at myself for singi } \\
\text { then point out that though it } \\
\text { feeling like a killjoy make } \\
\text { its so damn catchy. Not go } \\
\text { be annoyed by how catchy the } \\
\text { the lyrics are appalling. igno } \\
\text { I love the music but not the } \\
\text { I object to it on principle ! } \\
\text { it 's so catchy I can't help }\end{array}$ \\
\hline
\end{tabular}

Figure 2: Concordances of 'but' in response to hearing the song

Some respondents acknowledged that the way they felt about the tune was very different to how they felt about the lyrics and/or video. Six percent appeared to try and justify why they would sing or dance to the song; the reason being that the tune itself was good or 'catchy' (see above), although the co occurrence of catchy and but shown in Figure 2, is further indication of conflict.

Hearing the song provoked strong reactions in $30.22 \%$ of the respondents providing additional comments. Some were overtly physical and/or indicative of protest - 'rip my own ears off', 'boo at the DJ until he changed the song' - others suggested (feminist) activism. Reactions included respondents talking to others about the song, or taking to social media to express their views. Five respondents said that they would parody the song, or evoke existing parodies, whilst another made up their own, subversive lyrics: 'sing other words to the song (Robin Thicke is a douchebag...)'. Respondents who indicated that they would leave the dancefloor if they heard the song said that they would explain their choice to others, with one noting that they would 'begin a conversation with those around me about misogyny'. The terms tell (6), discuss/ion (4), explain (5), conversation (2), as well as the keywords rant (4), complain (5) and moan (2) suggest that hearing Blurred Lines was enough to begin debates. One respondent noted they would actively defend the song on hearing it, and three respondents said that they would listen to the song in order to try and understand the controversy around it. Thus, despite a majority of respondents suggesting that they did not like the song, there were those who liked it, and those who were conflicted in some way about the song. In order to interrogate what aspects of the song in particular might cause such conflict, we asked our respondents specifically about the music video (section 5.2) and then the song's lyrics (section 5.3).

\subsection{Visual Representations of Women/Men}

Thaller and Messing (2014:624) argue that '[1]yrical content can get lost in a strong beat, but images are typically more obvious and, thus, significantly more impactful'. Separating the music video from the lyrics seemed to generate majority agreement amongst respondents. A link to the censored version of the video was embedded in the questionnaire, and 790 respondents gave their opinions by selecting from the trichotomy of disliked it (74\%), liked it $(11 \%)$ and not having an opinion $(15 \%)$. When asked about the video, 57 respondents (out of 1331 across two questions, $4.28 \%$ ) suggested that the content of the music video to Blurred Lines was similar to that of other music videos: "what they do is no worse or more suggestive/offensive than in a hundred other music videos'. The idea Blurred Lines merely echoes the representations of men and women made in the wider music industry recurred throughout the questionnaire.

\subsubsection{Women in the video}

Respondents were asked specifically about the representation of women and men in the video, and responses tended to fall into particular semantic fields. 670 respondents offered their perspective on the women in the video (10,462 words) and 631 made comments about the men 
(8,528 words). Table 4 shows the top 50 lexical keywords relating to women's calculated using Wmatrix. The corresponding data for men's representation is considered in section 5.2.2. The keywords are ordered according to statistical saliency, and the key semantic domains (see below) are ordered according to keyness score. The keywords are grouped according to semantic categories. For example, terms such as prop, accessories and degraded are all statistical keywords that contribute to a discourse of female objectification.

\begin{tabular}{|c|c|c|}
\hline Category & Keywords & Total \\
\hline Objectification & $\begin{array}{l}\text { objectified (116), objects (69), sexualised (27), exploited (24), portrayed (22), } \\
\text { props (20), degraded/ing (23), objectification ( } 8 \text {, passive ( } 8) \text {, demeaning ( } 7) \text {, } \\
\text { abused (5), accessories (4), objectifying (4), objectifies (4) }\end{array}$ & 341 \\
\hline $\begin{array}{l}\text { Physical } \\
\text { appearance }\end{array}$ & $\begin{array}{l}\text { naked (47), attractive (23), appear (23), nudity (11), clothed (9), beautiful (17), } \\
\text { pretty (23), wearing (14), bodies (11), topless (7), clothes (14), dressed (11), } \\
\text { scantily (6), look like (12), skinny (8), look bored (5), clad (5), nude (6), } \\
\text { underwear (4), window dressing (4), underdressed (3) }\end{array}$ & 263 \\
\hline Agency & $\begin{array}{l}\text { treated (29), exploited (24), used (28), passive (8), submissive (6), choice (12), } \\
\text { agency (7), objectified (116), complicit (4) }\end{array}$ & 234 \\
\hline $\begin{array}{l}\text { Positive } \\
\text { descriptions of } \\
\text { women }\end{array}$ & $\begin{array}{l}\text { attractive, (23), beautiful (17), pretty (23), fun (10), enjoying themselves (4), } \\
\text { empowered (4), sexy (5), young (13) }\end{array}$ & 99 \\
\hline $\begin{array}{l}\text { Nominal } \\
\text { references to } \\
\text { women }\end{array}$ & models (14) dancers (10), woman (14), animals (8), girls (12) & 58 \\
\hline Women's actions & paid (40), dancing around (4), appearing (5) & 49 \\
\hline $\begin{array}{l}\text { Negative } \\
\text { descriptions of } \\
\text { women }\end{array}$ & $\begin{array}{l}\text { skinny (8), vapid (5), look bored (5), complicit (4), window dressing (4), vacant } \\
(5)\end{array}$ & 31 \\
\hline
\end{tabular}

\section{Table 4: Semantic grouping of top 50 lexical keywords: women in the video}

The discourse of objectification was prominent within respondents' comments about women in the video, with individuals indexing discourses of sexualisation; 'they are objectified and are displayed as there purely for the pleasure of the men in the video. They are dancing around wearing very little (or nothing in some scenes), for the entertainment of the men'. $315(47.01 \%)$ respondents to this question commented on the objectification of the women in the video: the word objectified occurs 116 times in the responses to this question, and it is the most statistically salient lexical keyword. The relatively frequent use of this word and those in its semantic field indicates the strength of sexist interpretation of the video.

Semantic field analysis using Wmatrix revealed that after <People: Female>, <Without clothes> was the second most key semantic field compared with the BNC (Table 5). This field contains words including naked (69), nudity (13) and topless (74), and four respondents evaluated the women as 'too naked'. The fifth most salient semantic category is $<$ no respect $>$, containing 50 instances of the terms: degrade, demean, disrespect, humiliate, cheapen, bad name, disgrace and deride. However, close reading of responses that contained these terms indicated that 4 respondents blamed the women in the video for the lack of respect they felt the men in the video had for women in general. One respondent commented that the women were 'setting back the cause of women about 40 years'. Resistant discourses about women in the 
Blurred Lines video were exemplified by respondents who showed a dislike of the women, using condemnatory language such as ridiculous (12), stupid (15) and silly (5). <Foolish> is also a high-ranking key semantic domain, and the keywords vacant (5) and vapid (5) are also used to describe the women. These assessments, ironically, can be interpreted as expressing sexist sentiment, and in turn serve as indices of 'double entanglement' (see below) - although on the surface these are negative evaluations of the way that women are represented in the video, they are ultimately judgements about the women based on their appearance, and assumptions about their intelligence based on the way they look, which draws on the sexist notion that (female) physical attraction and intelligence are mutually exclusive.

\begin{tabular}{|c|c|c|c|c|c|}
\hline Semantic domain & $\begin{array}{l}\text { Freq. Q4 } \\
\text { (women in } \\
\text { the video) }\end{array}$ & $\begin{array}{l}\text { Relative } \\
\text { freq. in } B L \\
\text { data }\end{array}$ & $\begin{array}{l}\text { Freq. in } \\
\text { BNC } \\
\text { spoken } \\
\text { sampler }\end{array}$ & $\begin{array}{l}\text { Relative freq. } \\
\text { in BNC } \\
\text { spoken } \\
\text { sampler }\end{array}$ & $\begin{array}{l}\text { Log- } \\
\text { likelihood } \\
\text { scores }\end{array}$ \\
\hline People: Female & 200 & 2.01 & 875 & 0.09 & 825.85 \\
\hline Without clothes & 74 & 0.74 & 24 & 0 & 572.61 \\
\hline $\begin{array}{l}\text { The Media: TV, Radio and } \\
\text { Cinema }\end{array}$ & 133 & 1.34 & 562 & 0.06 & 557.1 \\
\hline No respect & 50 & 0.5 & 5 & 0 & 426.88 \\
\hline Music and related activities & 90 & 0.9 & 586 & 0.06 & 309.93 \\
\hline Relationship: intimacy and sex & 86 & 0.86 & 549 & 0.06 & 299.1 \\
\hline People: Male & 118 & 1.19 & 1829 & 0.19 & 232.84 \\
\hline Unmatched & 176 & 1.77 & 5684 & 0.58 & 154.17 \\
\hline $\begin{array}{l}\text { Judgement of appearance: } \\
\text { Positive }\end{array}$ & 90 & 0.9 & 1717 & 0.17 & 147.74 \\
\hline $\begin{array}{l}\text { Clothes and personal } \\
\text { belongings }\end{array}$ & 96 & 0.96 & 2080 & 0.21 & 138.75 \\
\hline Objects generally & 126 & 1.27 & 4156 & 0.42 & 106.88 \\
\hline Seem & 71 & 0.71 & 1482 & 0.15 & 106.66 \\
\hline Uninterested/bored/unenergetic & 26 & 0.26 & 170 & 0.02 & 89.35 \\
\hline Foolish & 30 & 0.3 & 264 & 0.03 & 87.72 \\
\hline Arts and crafts & 49 & 0.49 & 896 & 0.09 & 83.71 \\
\hline $\begin{array}{l}\text { Social Actions, States and } \\
\text { Processes }\end{array}$ & 40 & 0.4 & 746 & 0.08 & 67.09 \\
\hline Degree: Maximizers & 46 & 0.46 & 1015 & 0.1 & 65.21 \\
\hline Degree & 7 & 0.07 & 0 & 0 & 64.44 \\
\hline Comparing: Similar & 43 & 0.43 & 925 & 0.09 & 62.62 \\
\hline People & 77 & 0.77 & 2728 & 0.28 & 58.26 \\
\hline
\end{tabular}




\section{Table 5: Top 20 semantic domains: women in the video}

While the keyword groupings are useful starting point for observing trends in the language that respondents used to describe women in the Blurred Lines video, the volume and detail of responses required discourse-level analysis. To move our analysis beyond the level of the word, we used NVivo to thematically analyse responses to the video. Close reading of the responses was followed by a process of inductive coding where codes such as objectification, sexualisation, choice, passivity and negative judgments were found in responses to the women in the video. These represent competing discourses (insofar as it is difficult to actively choose and passively be objectified), which highlight the varied and complex nature of responses to Blurred Lines. We argue that the conflicting nature of some of the ways women are talked about in the video points to the presence of what McRobbie $(2007,2009)$ refers to as 'double entanglement', in which women are afforded social, educational and other liberties in exchange for compliance in normative femininity, which necessarily requires the rejection of feminist values. This is evident in the contradiction between interpretations of the video as 'objectifying' women, where women are the passive recipients of the 'male gaze', versus competing discourses of choice and empowerment, in which women are viewed as agents, in control, but where this agency depends on exploitation of sexuality and adherence to notions of normative femininity.

The broad theme of negative judgments relates to a range of discourses that respondents drew on in their comments about the women in the video. These varied from comments which deemed the women as bound by normative femininity - 'I feel sorry for them - they feel like they have to act and dress like that'- to deeming them as complicit in their own objectification; 'disrespecting themselves'- and desirous of fame; 'In the case of Emily Ratajkowski, I'm quite sure she was content to appear in such a video as she had an inkling it would further her career. She's certainly used the video in order to get further publicity, and no doubt receive a great income from that publicity since'. Yet responses to female representation were not all negative. Some viewed the women in a more positive way, and refuted the interpretation of them being sexualised or objectified: 'They are pretty. I like their makeup a lot and the outfits. I don't agree with the negative opinion that I've heard of the girls having been objectified'. Another individual commented that 'they look sexy, empowered, and look like they are having fun'. The co-existence of feminist discourses with a kind of disarticulation of feminism is again reminiscent of 'double entanglement': the idea that individual women are 'empowered' as a result of physical attractiveness only serves to reinforce normative ideals of femininity, which works against the idea of collective resistance to objectification.

Respondents also noted that choice applied to the women in the video. Most of the 114 comments relating to this discourse were critical of the women's decision to participate in the video. One respondent commented that 'I feel that the women have made poor choices about how they portray themselves and women to society. They have allowed themselves to be portrayed as sex objects easily available for the gratification of men'. However, $24(3.58 \%)$ were less critical, referring to the women's choice as simply being the decision of actors or professionals who were paid to do a job. Yet linked to the discourse of choice was that of passivity; 75 respondents $(11.19 \%)$ conceptualised the women in the video as passive and without agency, suggesting they were naïve and unaware of their impact on audiences: 'it's their choice to be in the video but I don't think they understand what they're doing or how much they're being exploited'. However, one respondent highlighted the need to differentiate between the actors in the music video and the portrayal of women: 'the women themselves are models paid for a day's work. The way they have been portrayed is a problem, not the women as 
individuals'. Furthermore, 20 respondents $(2.99 \%)$ indicated that they did not want to pass judgement on the women: 'it would be arrogant and belittling to assume that, as women, they were unable to think for themselves and make informed decisions'.

\subsubsection{Men in the video}

Most of the 661 respondents who commented on the men in the video had a negative reaction. Thematic coding produced the following inductive codes: attractive; control; clothing; negatively judged; professional; predatory behaviour; smug; sleazy. The broader code of negatively-judged related to a number of brief responses given which indicated distaste, such as 'ewww' or 'ugh'. These core themes reflect what was found when approaching this question using corpus tools: there are more negatively evaluative keywords than any other type (Table 6) and <Judgement of appearance: negative $>,<$ Selfish $>$ and $<$ No respect $>$ are all high-ranking key semantic domains (Table 7).

\begin{tabular}{|c|c|c|}
\hline $\begin{array}{l}\text { Semantic } \\
\text { category }\end{array}$ & Keywords & Total \\
\hline $\begin{array}{l}\text { Negative } \\
\text { descriptions of } \\
\text { men }\end{array}$ & $\begin{array}{l}\text { creepy (38), sleazy/sleezy (30), misogynistic (21), arrogant (18), sexist (17), } \\
\text { predatory (14), idiots (13), smug (13), disgusting (16), objectifying (10), } \\
\text { misogynists (9), slimey/slimy (12), pathetic (10), leering (7), chauvinistic (7), } \\
\text { assholes (7), gross (10), pervy (7), disrespectful (7), creeps (7), egotistical (6), } \\
\text { dickheads (6), abusive (6), pigs (7), wankers (5), smarmy (5), objectify (5), } \\
\text { lecherous (5), vile (5), perverts (4), douchebags (4), unpleasant (5), ignorant (5) }\end{array}$ & 341 \\
\hline $\begin{array}{l}\text { Male sexual } \\
\text { drive }\end{array}$ & $\begin{array}{l}\text { creepy (38), sleazy/sleezy (30), predatory (14), slimey/slimy (12), leering (7), pervy } \\
\text { (7), creeps (7), smarmy (5), lecherous (5), vile (5), perverts (4) }\end{array}$ & 134 \\
\hline $\begin{array}{l}\text { Physical } \\
\text { appearance }\end{array}$ & $\begin{array}{l}\text { clothed (24), fully (23), appear (18), dressed (15), look like (16), cool (10), suits } \\
\text { (9), clothes (11) }\end{array}$ & 126 \\
\hline Agency & $\begin{array}{l}\text { powerful (18), dominant (11), in control (11), power (18), dominance (6), superior } \\
\text { (6), objectify (5), treat (7), exploiting (5) }\end{array}$ & 87 \\
\hline Men's actions & $\begin{array}{l}\text { Leering (7), acting (9), behaving (5), behave (6), perpetuating (4), treat (7), } \\
\text { exploiting (5), enjoying themselves (4) }\end{array}$ & 47 \\
\hline $\begin{array}{l}\text { Positive } \\
\text { descriptions of } \\
\text { men }\end{array}$ & Powerful (18), cool (10), talented (4), sexy (5) & 37 \\
\hline
\end{tabular}

Table 6: Grouping of top 50 lexical keywords: men in the video

\begin{tabular}{|l|l|l|l|l|l|}
\hline Semantic domain & $\begin{array}{l}\text { Freq. in Q5 } \\
\text { (men in the } \\
\text { video) }\end{array}$ & $\begin{array}{l}\text { Relative } \\
\text { freq. in the } \\
\text { BL data }\end{array}$ & $\begin{array}{l}\text { Freq. in } \\
\text { BNC spoken } \\
\text { sampler }\end{array}$ & $\begin{array}{l}\text { Relative freq. } \\
\text { BNC spoken } \\
\text { sampler }\end{array}$ & $\begin{array}{l}\text { Log- } \\
\text { likelihood } \\
\text { scores }\end{array}$ \\
\hline People: Female & 234 & 2.92 & 875 & 0.09 & 1126.58 \\
\hline Unmatched & 259 & 3.24 & 5684 & 0.58 & 458.89 \\
\hline Selfish & 63 & 0.79 & 102 & 0.01 & 389.41 \\
\hline People: Male & 141 & 1.76 & 1829 & 0.19 & 373.31 \\
\hline $\begin{array}{l}\text { Judgement of appearance: } \\
\text { Negative }\end{array}$ & 93 & 1.16 & 628 & 0.06 & 352.13 \\
\hline
\end{tabular}




\begin{tabular}{|l|l|l|l|l|l|}
\hline $\begin{array}{l}\text { The Media: TV Radio and } \\
\text { Cinema }\end{array}$ & 75 & 0.94 & 562 & 0.06 & 270.27 \\
\hline $\begin{array}{l}\text { Music and related } \\
\text { activities }\end{array}$ & 62 & 0.77 & 586 & 0.06 & 198.19 \\
\hline No respect & 23 & 0.29 & 5 & 0 & 195.48 \\
\hline $\begin{array}{l}\text { Clothes and personal } \\
\text { belongings }\end{array}$ & 99 & 1.24 & 2080 & 0.21 & 182.34 \\
\hline Inability/unintelligence & 33 & 0.41 & 90 & 0.01 & 176.45 \\
\hline Seem & 83 & 1.04 & 1482 & 0.15 & 174.96 \\
\hline Without clothes & 24 & 0.3 & 24 & 0 & 165.16 \\
\hline Fear/shock & 43 & 0.54 & 398 & 0.04 & 139.03 \\
\hline Degree & 14 & 0.17 & 0 & 0 & 134.93 \\
\hline In power & 103 & 1.29 & 3064 & 0.31 & 134.06 \\
\hline Foolish & 33 & 0.41 & 264 & 0.03 & 115.13 \\
\hline Respected & 19 & 0.24 & 94 & 0.01 & 82.28 \\
\hline $\begin{array}{l}\text { Social Actions, States and } \\
\text { Processes }\end{array}$ & 39 & 0.49 & 746 & 0.08 & 77.78 \\
\hline Comparing: Similar & 40 & 0.5 & 925 & 0.09 & 67.54 \\
\hline Open; Finding; Showing & 55 & 0.69 & 1730 & 0.18 & 67.07 \\
\hline
\end{tabular}

Table 7: Top 20 semantic domains: men in the video

Close analysis of these negative judgements reveals a prevalence of words such as slimy (6), repulsive (3), sleazy (27) and creepy (40) that can be said to index a 'male sexual drive' discourse (Holloway, 1984). Inductive coding highlights the links that respondents made between discourses of predatory behaviour and perceived 'sleazy' attitudes of the men in the video. One respondent drew a parallel between how they perceived the behaviour of the men in the video to real-life situations they had witnessed; 'they look like the creepy older men hitting/perving on younger women in clubs'. Another indicated that she perceived them as intimidating; 'they're pretty pathetic, sexually immature, smug and predatory. Essentially, they're creepy and I wouldn't want to be in a dark alley with them. They make my skin crawl'. Others indexed discourses of objectification, control and dominance; 'I find all three of them vile, at times Robin Thicke looks at the women in a really creepy possessive way. I dislike how smug they are, these women are theirs, play-things'. There was a close link between the discourses around control and references to clothing. 138 respondents $(20.88 \%)$ perceived the men as dominant, partly because of how they were dressed; 'the men, unlike the women, are fully dressed and appear predatory - they appear to be inspecting the women on the basis of their physical appearance, and in a very objectifying way. I would say that overall they come across as extremely chauvinistic'. These allusions to male sexual dominance in combination with references to female passivity (section 5.2.1) indicate that respondents broadly view the representations of male artists in the video as propagating unequal power relations between 
men and women, which consequently feeds into a broader 'gender differences' discourse (Sunderland 2004).

However, there were also positive evaluations of the men in the video. Inductive coding produced the code of 'professional', reflecting responses which indexed a discourse viewing the men in the video as simply doing a job; 'all participating were professionals who were briefed as to the job requirements and accepted.' Further exploration of these more positive evaluations was undertaken, using semantic fields and keyword analysis. 31 respondents (4.7\%) commented that they viewed the men as simply doing their job, and 55 respondents (8.31\%) used words such as handsome (3 tokens), sexy (5) and hot (7), commenting that they were 'good looking, and look to be having a good time with the ladies' and 15 respondents (2.27\%) suggested Blurred Lines drew on standard representations of men in music videos: 'your average role of a man in a video - confident, attractive, rich, cool'. However, other respondents who used these terms took a more negative view: 'they think they are hot and they are openly perving on the girls dressed as meat'. Though responses clustered around particular discourses (such as female objectification and male dominance), respondents' use of such discourses were not uniformly positive or negative. In addition, men were more likely than the women to be depicted neutrally and less likely to be interpreted as unaware of their actions.

For responses to the video we also conducted collocation analysis for the lemmas MAN and WOMAN using WordSmith Tools. Comparing the two lists (Table 8) is useful for showing how men and women in the video are conceptualised. The collocates are ranked according to collocational strength, with an MI score of 3 or higher indicating high/salient rates of collocation. There were 10 collocates meeting this threshold for WOMAN but only two for MAN. Words that have the strongest relationship with WOMAN emphasise the women's nudity and physical appearance, as well as their objectification by the men in the video, where those that collocate with MAN are associated with misogyny and their relative clothed status. Table 8 shows that the top twenty collocates of WOMAN included words relating to the treatment of women that indicate feminist discourses (objectifies, objectification, demeaning, towards, degrading, scantily, clad, sexist, objectifying, repressed, power). Furthermore, 47 respondents suggested that women are objectified in similar ways in other music videos, with some suggesting that the objectification in Blurred Lines is of a particular, extreme level: 'objectified to the point where they are presented as if they weren't even people'.

\begin{tabular}{|l|l|l|l|l|l|l|l|l|}
\hline Rank & Collocates of WOMAN & MI & Freq. & Rank & Collocates of MAN & MI & Freq. \\
\hline 1 & objectifies & 4.45 & 5 & 1 & man & 7.77 & 13 \\
\hline 2 & those & 3.97 & 6 & 2 & a & 3.01 & 11 \\
\hline 3 & towards & 3.77 & 5 & 3 & dressed & 2.80 & 6 \\
\hline 4 & demeaning & 3.77 & 5 & 4 & portrayed & 2.65 & 5 \\
\hline 5 & treat & 3.60 & 9 & 5 & clothed & 2.61 & 12 \\
\hline 6 & scantily & 3.45 & 5 & 6 & fully & 2.53 & 12 \\
\hline
\end{tabular}




\begin{tabular}{|l|l|l|l|l|l|l|l|}
\hline 7 & clad & 3.45 & 5 & 7 & really & 2.53 & 5 \\
\hline 8 & objectify & 3.45 & 5 & 8 & around & 2.45 & 6 \\
\hline 9 & objectification & 3.31 & 5 & 9 & so & 2.30 & 6 \\
\hline 10 & these & 3.07 & 7 & 10 & other & 2.30 & 5 \\
\hline 11 & objectifying & 2.97 & 6 & 11 & all & 2.16 & 7 \\
\hline 12 & young & 2.53 & 7 & 12 & misogynistic & 2.01 & 5 \\
\hline 13 & made & 2.45 & 5 & 13 & way & 1.95 & 7 \\
\hline 14 & beautiful & 2.45 & 6 & 14 & than & 1.90 & 5 \\
\hline 15 & looking & 2.38 & 7 & 15 & who & 1.87 & 12 \\
\hline 16 & should & 2.31 & 6 & 16 & by & 1.80 & 10 \\
\hline 17 & while & 2.31 & 9 & 17 & the & 1.77 & 9 \\
\hline 18 & girls & 2.25 & 6 & 18 & about & 1.68 & 7 \\
\hline 20 & can & 2.19 & 7 & 20 & at & & \\
\hline
\end{tabular}

Table 8: Top 20 collocates of WOMAN/MAN in responses to the video

The analysis of respondents' accounts of the representation of men and women in the video to Blurred Lines reflects what Gill terms 'postfeminist sensibility' (2007a; 2007b); while the men are disparaged for their objectification of the women in the video, in turn descriptions of the women focus on physical appearance, and the kinds of descriptors used to talk about men and women in the video reinforce gender complementarity. Only men are described as 'creepy' or 'sleazy' and only women are described as 'pretty' or 'beautiful'. The positive evaluations of women also focus on the notion of individual, rather than collective, empowerment, and for some respondents that empowerment comes from the very objectification that others rail against (i.e. looking 'sexy'). This contradiction between the assessment of women as 'empowered' and 'objectified' again indicates a kind of 'double entanglement' (McRobbie 2007, 2009), reinforcing the assumption that to be a successful woman involves adhering to cultural ideals of feminine beauty. It is interesting that while respondents criticise the men in the video for their role in 'objectifying' the female models, the respondents also express criticism towards the women, commenting on their perceived unintelligence and compliance in their own objectification. This kind of critique can be viewed as a form of 'victim blaming', 
whereby responsibility is placed on those who are affected by sexism and misogyny, rather than its agents.

\subsection{Interpreting Lyrics}

After asking about views of the video, we provided a subset of lyrics for respondents to comment on: 'But you're an animal, baby, it's in your nature, just let me liberate you', 'That's why I'm gon' take a good girl', 'I know you want it', 'The way you grab me, must wanna get nasty', 'You the hottest bitch in this place', and 'I'll give you something big enough to tear your ass in two'. The lyrics were chosen because they were deemed the most contentious in terms of meaning and seemed to crystallise some of the messages of subject position (that of male heterosexuality). Analysis of responses to the lyrics suggested that four key themes were prominent: sexual agency and consent, descriptions and evaluations of the song, references to feminist discourses, and implicit meaning-making. These themes were evident in the keywords (Table 9), semantic domains analysis, and qualitative analysis.

\begin{tabular}{|c|c|c|c|c|c|c|}
\hline Rank & Item & $\begin{array}{l}\text { Freq. in } \\
\text { responses to } \\
\text { all lyrics }\end{array}$ & $\begin{array}{l}\text { Relative freq. in } \\
\text { responses to all } \\
\text { lyrics }\end{array}$ & $\begin{array}{l}\text { Freq. in } \\
\text { BNC spoken } \\
\text { sampler }\end{array}$ & $\begin{array}{l}\text { Relative freq. } \\
\text { in BNC spoken } \\
\text { sampler }\end{array}$ & $\begin{array}{l}\text { Log- } \\
\text { likelihood } \\
\text { scores }\end{array}$ \\
\hline 1 & $\operatorname{sex}$ & 529 & 1.55 & 12 & 0 & 3478.99 \\
\hline 2 & women & 311 & 0.91 & 141 & 0.01 & 1561.05 \\
\hline 3 & woman & 242 & 0.71 & 113 & 0.01 & 1207.35 \\
\hline 4 & rape & 141 & 0.41 & 2 & 0 & 936.85 \\
\hline 5 & song & 151 & 0.44 & 24 & 0 & 887.41 \\
\hline 6 & lyrics & 129 & 0.38 & 1 & 0 & 864.59 \\
\hline 7 & girl & 195 & 0.57 & 198 & 0.02 & 793.27 \\
\hline 8 & penis & 108 & 0.32 & 0 & 0 & 733.61 \\
\hline 9 & sexual & 114 & 0.33 & 6 & 0 & 727.13 \\
\hline 10 & attractive & 116 & 0.34 & 16 & 0 & 691.53 \\
\hline 11 & wants & 164 & 0.48 & 231 & 0.02 & 593.57 \\
\hline 12 & want & 346 & 1.02 & 1788 & 0.18 & 580.53 \\
\hline 13 & sexually & 77 & 0.23 & 1 & 0 & 512.4 \\
\hline 14 & bitch & 68 & 0.2 & 18 & 0 & 374.88 \\
\hline 15 & compliment & 53 & 0.16 & 2 & 0 & 342.96 \\
\hline 16 & thinks & 72 & 0.21 & 48 & 0 & 330.82 \\
\hline 17 & anal_sex & 46 & 0.14 & 0 & 0 & 312.46 \\
\hline 18 & animal & 56 & 0.16 & 16 & 0 & 305.2 \\
\hline 19 & consent & 47 & 0.14 & 3 & 0 & 296.76 \\
\hline
\end{tabular}




\begin{tabular}{|l|l|l|l|l|l|l|}
\hline 20 & girls & 72 & 0.21 & 79 & 0.01 & 285.45 \\
\hline
\end{tabular}

Table 9: Top 20 lexical keywords in Blurred Lines lyrics responses

Keyword and key semantic domain analyses (Table 10) showed that apart from words relating to gender and sexuality such as male, female, men, women, etc., the largest semantic field contained words pertaining to 'sex'. The word sex (1086 occurrences in the 3294 total responses to all the lyrics tested, 37,050 words) was the most frequent of these. It occurred as a keyword in the responses to each individual lyric, indicating that the song as a whole was interpreted as being about sex. The referent of it in 'I know you want it' was interpreted as referring to sex (rather than other possible interpretations such as a relationship, friendship, etc.), with 209 (37.52\%) of 547 respondents making this connection, and a further $66(11.85 \%)$ claiming it refers to rape.

\begin{tabular}{|c|c|c|c|c|c|}
\hline $\begin{array}{l}\text { Key semantic } \\
\text { domain }\end{array}$ & $\begin{array}{l}\text { Freq. in } \\
\text { responses to } \\
\text { all lyrics }\end{array}$ & $\begin{array}{l}\text { Relative freq. in } \\
\text { responses to all } \\
\text { lyrics }\end{array}$ & $\begin{array}{l}\text { Freq. in } \\
\text { BNC spoken } \\
\text { sampler }\end{array}$ & $\begin{array}{l}\text { Relative freq. } \\
\text { in BNC spoken } \\
\text { sampler }\end{array}$ & $\begin{array}{l}\text { Log- } \\
\text { likelihood } \\
\text { scores }\end{array}$ \\
\hline People: Female & 919 & 2.7 & 875 & 0.09 & 3816.13 \\
\hline $\begin{array}{l}\text { Relationship: } \\
\text { Intimacy and sex }\end{array}$ & 448 & 1.32 & 549 & 0.06 & 1708.63 \\
\hline People & 670 & 1.97 & 2728 & 0.28 & 1363.01 \\
\hline $\begin{array}{l}\text { Music and related } \\
\text { activities }\end{array}$ & 307 & 0.9 & 586 & 0.06 & 975.96 \\
\hline Wanted & 711 & 2.09 & 5302 & 0.54 & 820.47 \\
\hline Unmatched & 727 & 2.13 & 5684 & 0.58 & 792.18 \\
\hline $\begin{array}{l}\text { Language, speech } \\
\text { and grammar }\end{array}$ & 310 & 0.91 & 1105 & 0.11 & 693.16 \\
\hline Crime & 191 & 0.56 & 290 & 0.03 & 670.87 \\
\hline Evaluation: Bad & 183 & 0.54 & 656 & 0.07 & 407.62 \\
\hline No respect & 62 & 0.18 & 5 & 0 & 385.91 \\
\hline $\begin{array}{l}\text { Judgement of } \\
\text { appearance: } \\
\text { Negative }\end{array}$ & 164 & 0.48 & 628 & 0.06 & 348.87 \\
\hline No constraint & 104 & 0.31 & 250 & 0.03 & 294.77 \\
\hline People: Male & 242 & 0.71 & 1829 & 0.19 & 274.82 \\
\hline Allowed & 160 & 0.47 & 930 & 0.09 & 240.92 \\
\hline $\begin{array}{l}\text { Judgement of } \\
\text { appearance: } \\
\text { Positive }\end{array}$ & 218 & 0.64 & 1717 & 0.17 & 235.38 \\
\hline Polite & 66 & 0.19 & 103 & 0.01 & 229.22 \\
\hline
\end{tabular}




\begin{tabular}{|l|l|l|l|l|l|}
\hline Respected & 62 & 0.18 & 94 & 0.01 & 217.9 \\
\hline Thought, belief & 493 & 1.45 & 7031 & 0.72 & 187.71 \\
\hline Dislike & 80 & 0.23 & 286 & 0.03 & 178.52 \\
\hline Violent/Angry & 131 & 0.38 & 959 & 0.1 & 154.49 \\
\hline
\end{tabular}

Table 10: Top 20 key semantic domains in Blurred Lines lyrics responses

There are also 331 instances of words relating to rape and consent, including rape (181), rapey (33), consent (94) and anal rape (14), which all occur in the key semantic domain of <crime>. This indicates that references to sexual consent are prominent in responses to the lyrics. However, while consent is a keyword when responses to all lyrics are combined, when responses to each lyric are taken separately consent only appears as a keyword for 'The way you grab me, must wanna get nasty'. This suggests that respondents related this particular lyric to sexual consent more than any others. The most frequent use of this term related to the singer's implied consent: 'This line indicates that any sign of consent for any sort of physical interaction must be taken as consent to all sorts of physical interaction, including sex.' Therefore this lyric is largely interpreted as denoting implicit, not explicit, consent and lends itself to a consent-based reading of the lyrics that allude to sexual violence. There are also a relatively small number of key verbs - assuming (92 tokens), implies (35) and implying (27) which constitute references to the implicit nature of meaning-making. These verbs indicate how the song both presupposes shared meanings (the subject position) and implicates meanings that have to be uncovered by respondents, such as the referent of it in 'I know you want it'. These verbs only appear in the top 20 keywords for responses to the lyrics 'That's why I'm gon' take a good girl', 'I know you want it', and 'The way you grab me, must wanna get nasty'. This suggests that these lyrics in particular are deemed most open to interpretation, and less straightforwardly sexist or misogynistic. In other words, we can view these lyrics as indicating indirect sexism (Mills 2008).

There are 626 instances of words providing descriptions and evaluations of the song, a third of which carry negative connotations: disgust/ing (23 tokens), vile (7), offensive (20), and degrad/ing (25). The majority of the instances of derogatory (29 out of 30) come from responses to the lyric 'you the hottest bitch in this place', referring in particular to the term 'bitch', although it should be noted that not all of the respondents focusing on bitch see it as unproblematically or universally derogatory. For instance, one respondent commented that bitch was just part of the language used in rap music, and therefore it was not necessarily meant in a derogatory way. Only catchy (24 tokens in responses to the lyrics) can be described has having overtly positive connotations, but is mainly used in reference to the conflict between the catchy music and otherwise offensive lyrics (section 5.1).

The word liberate occurs 31 times, appearing as a high-ranking keyword in responses to the lyric 'But you're an animal baby, it's in your nature, just let me liberate you' and in $40 \%$ of cases refers positively to sexual liberation. However, only 5 cases $(16.13 \%)$ draw upon feminist readings of the word liberate, which is used to negatively evaluate the song: 'Women are just craaaazy for the sex. Naturally. (It is also a VERY clever play on the feminist call for female liberation, which Mr Thicko and his crew have recontextualised to mean 'let me get nasty with you in the bedroom'. Shakespeare eat yr heart out.)' This suggests that a minority of respondents are aware of different possible meanings of the word liberate, and perceived the meaning to have been exploited in the context of this song. 
However, whilst some respondents were bold in their assertions that a consent-based reading of the song was self-evident, others' use of terms such as assuming and implying demonstrate acknowledgement of the position that sexual coercion may be interpreted by 'reading between the lines'. For those opposing a consent-based reading, such coercion does not equate to sexual violence. While one person's interpretation of ' $\mathrm{I}$ know you want it' is that it explicitly relates to rape - 'I'm going to rape you/ You said no but you meant yes/ you don't have the ability to consent' - another's makes no such links to sexual violence - 'It = to have sex with him'. Such discrepancies and multiple interpretations of the lyrics help to explain the lack of consensus about the song's meaning.

\subsection{Debating Sexual Consent}

In order to ensure respondents considered the mass-media-endorsed interpretation of the song, we explicitly asked if they felt Blurred Lines said anything about sexual consent, using an open question format (551 respondents, 18,408 words). Some respondents were quite clear in their answers about whether or not the song did $(66 \%)$ or did not $(13 \%)$ relate to sexual consent, insofar as they wrote yes or no as (part of) their response. The remainder were unclear or undecided. Of the $13 \%$ who stated that Blurred Lines did not say anything about sexual consent, a common assertion was that the song portrayed a flirtatious encounter rather than forced sexual advances. Respondents of either position indicated that media coverage of the song had affected their own or others' interpretations of it: 'I think it has been all blown out of proportion'; 'I have read the controversy in the press so now, yes, I do think it applies to sexual consent'.

Even amongst the $66 \%$ who did relate the song to sexual consent, interpretations of consent were complex. Two respondents noted that, as women did not have a voice the song, it did not (or could not) say anything about consent, as there was no opportunity for the women to talk. Other respondents hesitated over the link between consent and rape: 'I get the impression none of the men would actually rape the girls in the video or in general, but, the sex wouldn't be entirely consensual'. The position expressed in this comment is complex, as the respondent considers 'rape' and not 'entirely consensual' sex as two different things, but for someone taking the position that 'rape' and 'no consent' are equal concepts, this position is untenable. We hypothesise that those taking the first position, that 'non-consensual' and 'rape' are different entities would be more likely to reject a consent-based reading of Blurred Lines.

Despite these different interpretations, when asked to use a Likert scale to indicate whether they thought the word 'rapey' - a term widely used in the mass media to debate Blurred Lines - could be used to describe the song, 74\% of 591 respondents agreed (with 52\% strongly agreeing). By contrast, only $14 \%$ of respondents disagreed (with just $3.4 \%$ strongly disagreeing). Thus, only $12 \%$ of respondents were undecided. Rapey was also considered problematic, due to its potential interpretation as trivialising sexual assault (Romano 2013): 'it's unfortunate that the media have described the track as 'rapey', since this infantilises what's going on'.

Finally, we asked our respondents what the term 'blurred lines' meant. The results for this question represented one of the strongest trends in our dataset: $329(59.40 \%)$ of 554 qualitative responses explicitly linked the term to rape, with a further $86(15.48 \%)$ suggesting that the song was not about rape but about sexual relations. Other, minority interpretations included reference to right and wrong $(40,7.27 \%)$ and to the singer and the object of his affections getting drunk $(28,5.10 \%)$. Only $22(3.95 \%)$ of respondents claimed not to know what the term 
meant, whilst just $6(1.06 \%)$ suggested that their interpretation of the term had been influenced by the media. Thus, despite the nuances of interpretation born out in the preceding analysis, the quantitative data suggests that the term 'blurred lines' is interpreted as relating to sexual consent. Therefore, those taking a consent-based reading seem to have justification for their position.

\section{Conclusions}

Through a combination of corpus linguistics and thematic qualitative analysis of responses to an online questionnaire, we have highlighted the ways in which listeners of Blurred Lines often possess conflicted positions of intelligibility for the song, as opposed to evaluating the song simply as positive or negative. Furthermore, our analysis shows that some respondents explicitly referenced discourses of feminism or the song's portrayal in the mass media as influencing their interpretations, although this was a minor trend. In general, the respondents seemed to largely reject the song's subject position, which would lead the listener to empathise with Thicke, with the majority accepting a consent-based reading of the song. However, our analysis also showed that listeners can have alternative readings of the song, which do not represent either of these established positions. Part of the explanation for this is that in order to make sense of the lyrics, listeners had to rely on implicit forms of meaning-making; because listeners had to work out what the lyrics meant, this led to a degree of variability of interpretation.

Those respondents who accepted that the representations of men, women, and sexuality in the song were conventional in terms of music videos, and those who argued that the lyrics were merely playful, seemed more likely to perform the kind of 'uncritical consumption' that Gauntlett (2008: 27), discussed in section 3, refers to. However, it is important to note that whilst people can be interpellated by the subject position in the song, they could also be interpellated by the mass media's endorsement of the consent-based reading of the song. So whilst people can resist interpellation by rejecting the song, they could simultaneously be being interpellated by social messages from elsewhere; readers taking the consent-based view of the song are insubordinate to the subject position in the song, but simultaneously subordinate to the subject-position of the mass media. Arguably then, it is those who are conflicted about the song (not those taking up the subject position or the consent-based reading exclusively) who are actively engaging in negotiating its meaning.

We also discussed how elements of conflict evident in the reception of Blurred Lines also point to post-feminist stances reminiscent of McRobbie's notion of 'double entanglement' (2007, 2009). For example, some respondents positively evaluate the female models in the video to Blurred Lines by describing them as 'empowered', despite their apparent relative subordinate position as 'playthings' or 'window dressing'. In addition, our respondents showed an awareness of the subject position of the song, but did so with a corresponding awareness of popular resistant discourses that linked the song explicitly to debates about consent, rape, and rape culture.

This research points to the importance of considering audience reception data in analyses of sites of popular culture, as this can tell us more about their potential influence on consumers than text analysis alone. It is only by garnering opinion on the ways in which gendered norms and sexual practices are negotiated in media texts that we can come to an understanding of the way individuals make sense of the texts themselves, and how these link to normative understandings of gender and sexuality. 


\section{Appendix A: The Questionnaire}

A group of researchers at $\mathrm{X}$ are conducting research about the song Blurred Lines and we would like to gather your thoughts and opinions on the song. By completing the following questions you agree to participate in this survey. The information you provide will be used for research purposes and will not be used in a manner which would allow identification of your individual responses. Thank you for agreeing to take part in this research.

1. Please indicate your gender and age using the table below.

\begin{tabular}{|l|c|c|c|c|c|c|c|}
\hline & $18-21$ & $22-25$ & $26-30$ & $31-35$ & $36-40$ & $41-45$ & $46+$ \\
\hline Male & & & & & & & \\
\hline Female & & & & & & & \\
\hline Prefer not to say & & & & & & & \\
\hline
\end{tabular}

2. Which of the following would you do? Select all that apply.

(i) Sing along, (ii) Buy the song, (iii) Stream the song, (iv) Dance, (v) Change the radio/television station, (vi) Leave the dancefloor, (vii) Other (please specify)

The next couple of questions are about the music video. The Blurred Lines video can be found here: https://www.youtube.com/watch? $\mathrm{v}=\mathrm{yyDUC1LUXSU}$

3. What is your opinion of the music video?

(i) I like it, (ii) I dislike it, (iii) I don't have an opinion on it

4. What are your feelings about the women in the video?

5. What are your feelings about the men in the video?

The next question is about some of the song lyrics. The full set of lyrics can be found here: http://www.metrolyrics.com/blurred-lines-lyrics-robin-thicke.html

6. What do you think the following lyrics of the song mean?

(i) 'But you're an animal, baby, it's in your nature, just let me liberate you'

(ii) 'That's why I'm gon' take a good girl'

(iii) 'I know you want it'

(iv) 'The way you grab me, must wanna get nasty'

(v) 'You the hottest bitch in this place'

(vi) 'I'll give you something big enough to tear your ass in two'

7. Has reading these lyrics changed your view of the song?

8. What do you think the phrase 'blurred lines' refers to?

9. Do you think the song says anything about sexual consent? Please explain your answer.

10. In the media, the song has been described as 'rapey'. How far do you agree with this?

(i) Strongly agree, (ii) Agree, (iii) Neither agree nor disagree, (iv) Disagree,

(v) Strongly disagree

\section{References}

Baker, P. 2006. Using Corpora in Discourse Analysis. London: Continuum.

Baker, P. 2014. Using Corpora to Analyse Gender. London, Bloomsbury. 
Bates, L. 2014. Everyday Sexism. Simon and Schuster: London.

Baxter, H. and R. L. Coslett. 2014. The Vagenda: A Zero Tolerance Guide to the Media. London: Square Peg.

Braun, V. and Clarke, V. (2006) Using thematic analysis in psychology. Qualitative Research in Psychology, 3 (2). pp. 77-101.

Bushwald, E., P.R. Fletcher and M. Roth. 2005. Transforming a Rape Culture (second edition). Minneapolis: Milkweed Editions.

Butler J. 1990. Gender Trouble: Feminism and the Subversion of Identity. New York: Routledge.

Butler, J. 1993. Bodies that Matter On the Discursive Limits of 'Sex'. New York: Routledge.

Channel 4. 2014. Krishnan Guru-Murthy interviews Pharrell Williams, 28 May 2014. Accessed 22 October 2014. www.youtube.com/watch?v=uHP-_JbSP2c.

Dibben, N. 1999. 'Representations of femininity in popular music.' Popular Music 18:331-355.

Ducker, E. 2013. Q \& A: Veteran music video director Diane Martel on her controversial videos for Robin Thinke and Miley Cyrus. Grantland June 26 2013. Accessed October 222014. http://grantland.com/hollywood-prospectus/qa-veteran-music-video-director-diane-martel-onher-controversial-videos-for-robin-thicke-and-miley-cyrus/.

Durham, A. 2012 ''Check on it', Feminist Media Studies, 12:1, 35-49.

Emerson, R. A. 2002. ' Where my girls at?' Negotiating black womanhood in music videos.' Gender \& Society 16 (1):115-135.

Fairclough, N. 1992. Discourse and Social Change. Cambridge: Polity Press.

Francis, W. N. and H. Kučera. 1982. Frequency Analysis of English Usage: Lexicon and Grammar. Boston: Houghton Mifflin.

Gauntlett, D. 2008. Media, Gender and Identity: An Introduction. London: Routledge.

Gill, R. 2006. Gender and the Media. Cambridge: Polity Press.

Goffman, E. 1976. Gender Advertisements. New York: Harper Colophon Books.

Hansen, C.H. and R. D. Hansen. 1990. 'The influence of sex and violence on the appeal of rock music videos.' Communication Research 17 (2):212-234.

Horvarth, M. A. H., P. Hegarty, S. Tyler and S. Mansfield. 2012. "Lights on at the end of the party': Are lads' mags mainstreaming dangerous sexism?' British Journal of Psychology 103:454471.

Holloway, W.. 1984. 'Gender difference and the production of subjectivity' In Changing the Subject: Psychology, Social Regulation and Subjectivity. Edited by J Henriques, W Holloway, C Urwin, C Venn and V Walkerdine. London: Methuen. pp. 227-339.

IFPI. 2014. IFPI Digital Music Report 2014. Online. Accessed June 292014. http://ifpi.org/downloads/Digital-Music-Report-2014.pdf.

Jaworska, S. \& Krisshnamurthy, R. 2012. 'On the F word: A corpus-based analysis of the media representation of feminism.' Discourse \& Society 23 (4):401-431.

Johnson, J.D., M. S. Adams, L. Ashburn, and W. Read. 1995. 'Differential gender effects of exposure to rap music on African American adolescents' acceptance of teen dating violence.' Sex Roles 33 (7-8):597-605.

Kalof, L. 1999. 'The effects of gender and music video imagery on sexual attitudes.' The Journal of Social Psychology 139 (3):378-385.

Kelley, L 2008 'Paradoxical progress: responding to sexual violence', Soundings, 39 (8):128-135.

Kubrin, C.E. 2005. 'Gangsta's, Thugs and Hustlas: Identity and the Code of the Street in Rap Music.' Social Problems 52:360-378.

Lai, J. 2013. 'Blurred Lines' is cocky, yes. But rapey? No. Slate 27 June 2013. Accessed October 22 2014.

www.slate.com/blogs/xx_factor/2013/06/27/robin_thicke_s_blurred_lines_is_cocky_yes_but _rapey_and_misogynistic_no.html.

McRobbie, A. 2007. 'Post-feminism and popular culture', Feminist Media Studies, 4:3, 255-264. 
McRobbie, A. 2009. The Aftermath of Feminism: Gender, Culture and Social Change. London: Sage. Mills, S. 2008. Language and Sexism. London: Routledge.

NVivo. 2012. NVivo qualitative data analysis software. QSR International Pty Ltd. Version 10.

Project Unbreakable. 2014. Home. Accessed October 31 2014. http://project-unbreakable.org/.

Railton, P. and Watson, P. 2005. 'Naughty girls and red blooded women: representations of female heterosexuality in music video', Feminist Media Studies, 5:1; 51-63

Rayson, P. 2009. Wmatrix: A web-based corpus processing environment. Computing Department, Lancaster University. http://ucrel.lancs.ac.uk/wmatrix/

Romano, T. 2013. 'Blurred Lines,' Robin Thicke's Summer Anthem, Is Kind of Rapey'. The Daily $\begin{array}{lllllll}\text { Beast } & 17 & \text { June } & 2013 . & \text { Accessed } & \text { October }\end{array}$ www.thedailybeast.com/articles/2013/06/17/blurred-lines-robin-thicke-s-summer-anthem-iskind-of-rapey.html.

Seidman, S. A. 1992. 'An investigation of sex-role stereotyping in music videos.' Journal of Broadcasting \& Electronic Media 36:209-216.

Skeggs, B. 1994. 'Refusing to be Civilized: 'Race', Sexuality and Power.' In The Dynamics of 'Race' and Gender: Some Feminist Interventions, edited by H. Afshar and M. Maynard. London: Taylor \& Francis. pp.106-126.

Sommers-Flanagan, R., J. Sommers-Flanagan and B. Davis. 1993. 'What's happening on music television? A gender role content analysis. Sex Roles 28 (11-12):745-753.

Sunderland, J. 2004. Gendered Discourses. Basingstoke: Palgrave Macmillan.

Thaller, J. and J. T. Messing. 2014. '(Mis)perceptions around intimate partner violence in the music video and lyrics for 'Love the Way You Lie'. Feminist Media Studies 14:623-639.

Wallis, C. 2011. 'Performing gender: A content analysis of gender display in music videos.' Sex Roles 64 (3-4):160-172.

Walter, N. 2010. Living Dolls: The Return of Sexism. London: Virago.

Ward, L. M., E. Hansbrough and E. Walker. 2005. 'Contributions of music video exposure to black adolescents' gender and sexual schemas.' Journal of Adolescent Research 20 (2):143-166.

Werner, V. 2012. Love is all around: a corpus-based study of pop lyrics. In: Corpora, 7 (1):19-50. 